\title{
Study the effect of mifepristone on clinical symptoms and its side effects in patients with fibroid uterus
}

\author{
Umbreen Seher, Nidhi Chauhan*, Mishu Mangla
}

Department of Obstetrics and Gynecology, Himalayan Institute of Medical Sciences, SRHU, Dehradun, Uttarakhand, India

Received: 06 November 2018

Accepted: 16 November 2018

*Correspondence:

Dr. Nidhi Chauhan,

E-mail: manumanan@rediffmail.com

Copyright: (c) the author(s), publisher and licensee Medip Academy. This is an open-access article distributed under the terms of the Creative Commons Attribution Non-Commercial License, which permits unrestricted non-commercial use, distribution, and reproduction in any medium, provided the original work is properly cited.

\section{ABSTRACT}

Background: Fibroid can lead to a variety of clinical symptoms including pain, menorrhagia, and lump in abdomen. The availability of a safe and efficient medical management options for symptomatic fibroid is of considerable clinical and public health importance. The present study is designed to see the safety and efficacy of mifepristone in the medical management of uterine fibroids.

Methods: The study was conducted in the Department of Obstetrics and Gynaecology, Himalayan Institute of Medical Sciences, Swami Ram Nagar, Dehradun over a period of 12 months. A total of 40 patients were included in the study.

Results: Amount of bleeding was assessed by PBAC score, which significantly reduced by $83.9 \%$ at the end of treatment. And $62 \%$ patients developed amenorrhoea due to mifepristone. Similarly, pain abdomen/dysmenorrhoea was assessed by Numeric Pain Rating Scale, which also showed a significant reduction in 55\% patients with no pain at the end of 3 months.

Conclusions: The study clearly shows that Mifepristone is a safe and effective option to manage fibroid uterus and its associated symptoms.

Keywords: Clinical symptoms, Fibroid, Mifepristone

\section{INTRODUCTION}

Fibroid can lead to a variety of clinical symptoms including pain, menorrhagia, and lump in abdomen. Anterior wall fibroids can cause pressure symptoms on the bladder and increased frequency of micturition. Posterior wall fibroids lead to spontaneous abortions, infertility etc. The severity of symptoms mainly depends on number of fibroids, their size and site. ${ }^{1}$ The availability of a safe and efficient medical management options for symptomatic fibroid is of considerable clinical and public health importance. New technologies have given additional minimally invasive techniques as cryoablation, percutaneous laser ablation, "magnetic resonance imaging (MRI)-guided focused ultrasound" and transvaginal uterine artery ablation are currently under trial. Recently, new medications have been proposed, and are used as long-term medical therapy options for symptomatic fibroids. ${ }^{2}$

"Mifepristone" (RU 486) on the other hand is described as a "progesterone receptor modulator" with antagonistic action. It inhibits the progesterone receptors by strongly binding to them, and little bit to the "estrogen receptors" and upregulates the "androgen receptors". 3 It is synthesized from its precursor norethindrone, and competitively binds and inhibits the progesterone receptors. 4 It also leads to amenorrhoea by delaying or inhibiting ovulation. It reduces the menstrual blood loss by causing direct suppressive action on the endometrium 
as well as on reduction of the stromal vascular endothelial growth factor (VEGF). ${ }^{5}$ In recent days, fibroid uterus has become a common finding on ultrasound, which requires treatment. The present study is designed to see the safety and efficacy of mifepristone in the medical management of uterine fibroids.

\section{METHODS}

The study was conducted in the Department of Obstetrics and Gynaecology, Himalayan Institute of Medical Sciences, Swami Ram Nagar, Dehradun over a period of 12 months. Subjects were recruited from Obstetrics and Gynaecology OPD at Himalayan Institute of Medical Sciences, Dehradun, after taking a written and Informed consent. Follow up of each subject was done for 3 consecutive months.

The type of the study was experimental, pre and post. Sample size of the study includes 40 subjects with uterine leiomyoma from the Obstetrics and Gynaecology OPD over a period of one year and follow up was done for 3 months.

\section{Inclusion criteria}

Women of reproductive age group (18-49years) with

- Symptomatic fibroids

- Asymptomatic patients showing fibroid of size $>2.5 \mathrm{~cm}$ on ultrasonography.

\section{Exclusion criteria}

- Presence of pregnancy or lactation

- Women desirous of pregnancy

- Suspicious of uterine, ovarian or endometrial malignancies

- H/o hormonal treatment over past 3months

- Presence of any renal, respiratory or heart disease, PID or any other adnexal pathology

- Uterine fibroid $>20$ weeks size

- Atypical endometrial hyperplasia

- Those having contraindication for use of mifepristone.

Study tools: Relevant medical, obstetric and menstrual history was taken, past illness if any, relevant personal history, family history, was also be included.

- Case reporting form

- Endometrial biopsy curette

- Histopathology

- Ultrasonography

- Blood investigations- Haemoglobin, Liver function Test, Kidney function test, TSH

- Pictorial blood loss assessment chart (PBAC)

- Numeric pain rating scale.

\section{RESULTS}

The most common complaint associated with fibroid uterus was menorrhagia in $24(60 \%)$ cases. $8(20 \%)$ cases were asymptomatic, but with a fibroid of $>2.5 \mathrm{~cm}$. Pain abdomen and dysmenorrhoea were seen in 8(20\%) patients (Table 1).

Table 1: Symptom wise distribution of cases.

\begin{tabular}{|lll|}
\hline Symptoms & Frequency $(\mathbf{n = 4 0})$ & Percentage \\
\hline Menorrhagia & 24 & 60 \\
\hline $\begin{array}{l}\text { Pelvic pain/ } \\
\text { dysmenorrhoea }\end{array}$ & 8 & 20 \\
\hline Asymptomatic & 8 & 20 \\
\hline Total & 40 & 100 \\
\hline
\end{tabular}

In this study, mean baseline PBAC score decreased by $71.20 \%$ at 1 month and significantly by $83.29 \%$ at the end of 3 months treatment with Mifepristone. 29 patients had menorrhagia at the time of recruitment, out of which 18 patients $(62 \%)$ developed amenorrhoea at 1 month, which continued till 3 months of treatment with mifepristone in $37(92.5 \%)$ the PBAC score was between 0-50 at the end of treatment (Table 2).

Table 2: Comparison of cases according to PBAC score $(n=40)$.

\begin{tabular}{|lllllll|}
\hline PBAC & \multicolumn{2}{l}{ At 0 month } & \multicolumn{2}{l}{ At 1 month } & \multicolumn{2}{l}{ At 3 months } \\
score & No. & $\%$ & No. & $\%$ & No. & $\%$ \\
\hline $0-50$ & 19 & 47.5 & 33 & 82.5 & 37 & 92.5 \\
\hline $51-100$ & 6 & 15 & 5 & 12.5 & 2 & 5 \\
\hline $101-150$ & 9 & 22.5 & 2 & 5 & 1 & 2.5 \\
$151-200$ & 2 & 5 & 0 & 0 & 0 & 0 \\
\hline$>200$ & 4 & 10 & 0 & 0 & 0 & 0 \\
\hline Mean & $79.28 \pm 70.90$ & $22.83 \pm 37.13$ & $13.00 \pm 24.43$ \\
\hline
\end{tabular}

In this study, there was a significant reduction in pain score with treatment. $55 \%$ patients had no pain in $22.5 \%$ patients the pain score was 2 .

Table 3: Comparison of cases according to Pain Score $(n=40)$.

\begin{tabular}{|lllllll|}
\hline Pain & At 0 month & At 1 month & At 3 months \\
score & No. & \% & No. & \% & No. & \% \\
\hline 0 & 0 & 0 & 22 & 55.0 & 22 & 55.0 \\
\hline 2 & 3 & 7.5 & 3 & 7.5 & 9 & 22.5 \\
\hline 3 & 1 & 2.5 & 3 & 7.5 & 6 & 15.0 \\
\hline 4 & 8 & 20.0 & 8 & 20.0 & 3 & 7.5 \\
\hline 5 & 8 & 20.0 & 2 & 5.0 & 0 & 0 \\
\hline 6 & 6 & 15.0 & 2 & 5.0 & 0 & 0 \\
\hline 7 & 4 & 10.0 & 0 & 0 & 0 & 0 \\
\hline 8 & 10 & 25.0 & 0 & 0 & 0 & 0 \\
\hline Total & 40 & 100 & 40 & 100 & 40 & 100 \\
\hline
\end{tabular}

Significantly there were no patients in the pain score level from 5 to 8 at the end of treatment (Table 3). In this 
study, total 40 patients were taken, out of which 4 patients were unmarried, therefore, endometrial biopsy was not done in them, and were excluded. Post-treatment,
$1(2.7 \%)$ out of 36 cases developed endometrial hyperplasia, which was simple hyperplasia without atypia (Table 4).

Table 4: Endometrial changes before and after treatment.

\begin{tabular}{|lllll|}
\hline HPE report & Before treatment & & After treatment & Percent \\
\hline Atrophic endometrium & Frequency $(\mathbf{n = 3 6 )}$ & Percent & Frequency $(\mathbf{n = 3 6})$ & 0.00 \\
\hline Endometrial Hyperplasia & 1 & 2.7 & 0 & 2.7 \\
\hline Late secretory phase & 0 & 0.00 & 1 & 11.16 \\
\hline Post ovulatory phase & 5 & 13.8 & 4 & 0.00 \\
\hline Proliferative phase & 2 & 5.5 & 0 & 72.22 \\
\hline Secretory Phase & 13 & 36.1 & 26 & 13.8 \\
\hline Total & 15 & 41.6 & 5 & 100.00 \\
\hline
\end{tabular}

Table 5: Side-effects of treatment.

\begin{tabular}{|c|c|c|c|c|}
\hline \multirow{2}{*}{ Side effects } & \multicolumn{2}{|l|}{ At 1 month } & \multicolumn{2}{|l|}{ At 3 months } \\
\hline & Frequency $(n=40)$ & Percentage & Frequency $(n=40)$ & Percentage \\
\hline Nausea & 4 & 10 & 8 & 20 \\
\hline Vomiting & 1 & 2.5 & 2 & 5 \\
\hline Diarrhoea & 2 & 5 & 2 & 5 \\
\hline Hot flushes & 1 & 2.5 & 2 & 5 \\
\hline Weight gain & 2 & 5 & 4 & 10 \\
\hline Mood swings & 3 & 7.5 & 6 & 15 \\
\hline Headache & 9 & 22 & 13 & 32 \\
\hline Weakness & 14 & 35 & 19 & 47 \\
\hline Fatigue & 13 & 32 & 18 & 45 \\
\hline Loss of libido & 0 & 0 & 0 & 0 \\
\hline
\end{tabular}

Most common side-effect of mifepristone in present study was weakness and fatigue, which increased with treatment. At 1 month weakness was seen in $35 \%$ cases, which increased to $47 \%$ at 3 months. And Fatigue increased from $32 \%$ at 1 month to $45 \%$ at 3 months. Other side effects as nausea, vomiting, mood swings were also present, but less common. The percentage of cases with diarrhoea were same (5\%), before and after 3 months of treatment. No case experienced loss of libido in present study (Table 5).

\section{DISCUSSION}

In present study, menorrhagia was the most common fibroid related symptom seen in 60 per cent patients. Pain abdomen and dysmenorrhoea was seen in $20 \%$ patients. Seth et al. in their study found that abnormal and excessive uterine bleeding was the commonest problem seen in 77 patients $(93.96 \%)$ followed by heaviness in lower abdomen in $22(26.83 \%)$ and pain in $18(21.95 \%)$ for which they came to hospital. ${ }^{6}$ Another study conducted by Sinha et al. showed that 40 per cent patients had menorrhagia as the major complaint, followed by pain abdomen in 26 per cent. ${ }^{7}$ Therefore, it was concluded that menorrhagia is the most common symptom associated with uterine fibroid.

We saw that in present study, there was a significant decrease in the mean PBAC score. There was a decrease by $71.20 \%$ at 1 month of treatment, and by $83 \%$ at the end of 3 months of treatment. And 62 per cent patients became amenorrhic at the end of treatment.

Kulshrestha et al. in their study showed that the PBAC score significantly declined from 253 to 19 in patients who were given $25 \mathrm{mg}$ mifepristone daily. And the PBAC score declined from 289 to 104 in patients who were given $10 \mathrm{mg}$ mifepristone daily, after 3 months of completion of the treatment. ${ }^{1}$ Sabita et al. did a study in which the mean blood loss was corrected in $100 \%$ of the patients. ${ }^{8}$ Another study by Eisenger et al. showed that there was a significant difference of 7 . 1units in the menstrual blood loss index in the two groups after treatment. ${ }^{9}$ One more study conducted by Arora et al. it was found that all patients became amenorrhic at the end of treatment, resulting in a PBAC score of "zero". ${ }^{10}$ This concluded that mifepristone is an effective choice of treatment for fibroid and related symptoms in 
perimenopausal age group and in patients who want to avoid surgical treatment.

In present study another important complaint was pelvic pain. The results showed that there was a significant reduction in pain, as measured by the "Numeric Pain Control Scale". By the end of 3 months of treatment, 55 per cent patients were completely relieved of pain. In one study by Fiscella et al. there was no significant improvement in pain, when assessed by the "McGill pain questionnaire". ${ }^{11}$ Shikha Seth et al. gave $25 \mathrm{mg}$ mifepristone daily for 3 months. The results showed a significant decline in the symptom of pain, which was " 4 " at baseline to " 2 " at the end of treatment. ${ }^{6}$

In present study, no patient had endometrial hyperplasia at baseline, but one patient developed endometrial hyperplasia at the of end treatment, though it was without atypia. The volume of the fibroid also increased in this patient, and later ended up with hysterectomy. Bagaria et al. conducted a study, which showed that all patients had normal endometrium (proliferative or secretory) at the time of enrollment. And later after completion of the treatment, 12 of the 19 patients $(63.1 \%)$ who were given mifepristone developed endometrial hyperplasia compared the placebo group in which no patient had hyperplasia. Out of these 12 patients, one patient developed complex hyperplasia, while the rest developed simple hyperplasia without atypia. ${ }^{12}$ Seth et al. conducted a study in which $25 \mathrm{mg}$ mifepristone was given daily for a period of 3 months. Only 2 patients had a endometrial thickness of more than $20 \mathrm{~mm}$. They underwent endometrial biopsy, and the histopathology showed simple hyperplasia. ${ }^{6}$ In present study, many side effects of the drug were studied. The results concluded that 2 patients $(5 \%)$ had hot flushes at the end of treatment, and the most common side-effect was weakness present in 19 patients (47\%). Kulshrestha et al. did a study in which the most common side-effects were hot flushes $(7.1 \%)$ and weakness $(7.1 \%){ }^{1}$

Sudha et al. in their study showed that the only side effect present was fatigue, seen in 6 patients. ${ }^{13}$ In present study, fatigue was present in $18(45 \%)$ patients at the end of treatment with Mifepristone, and was a significant side effect. In a study by Bagaria et al there were no sideeffects like nausea, vomiting, fatigue, headache, weakness, hot flashes, diarrhoea, loss of libido in any patient after giving $10 \mathrm{mg}$ mifepristone. ${ }^{12}$ But in present study, almost all side effects were present. Loss of libido was the only side effect not seen in any of the patient before and after the treatment.

\section{CONCLUSION}

A significant reduction was seen in major symptoms i.e menorrhagia and pain after treatment with mifepristone and the side effects were minimal and not significant. The study shows that mifepristone is a safe and effective option to manage fibroid uterus and its associated symptoms, although long term follow up studies are required to study the recurrence of symptoms after stoppage of treatment.

\section{ACKNOWLEDGMENTS}

Authors would like to thank Mr. Deepak Kumar for his support during study.

Funding: No funding sources

Conflict of interest: None declared

Ethical approval: The study was approved by the Institutional Ethics Committee

\section{REFERENCES}

1. Kulshrestha V, Kriplani A, Agarwal N, Sareen N, Garg P, Hari S, et al. Low dose mifepristone in medical management of uterine leiomyoma - an experience from a tertiary care hospital from north India. Indian J Med Res. 2013;137(6):1154-62.

2. Tropeano G, Amoroso S, Scambia G, Levy BS. Management of Uterine Fibroids. Hum Reprod Update. 2007;14(3):812-23.

3. Spitz IM. Mifepristone: where do we come from and where are we going? Clinical development over a quarter of a century. Contracep. 2010; 82(5):442-52.

4. Cadepond, PhD F, Ulmann, MD, PhD A, Baulieu, MD, PhD EE. RU486 (mifepristone): mechanisms of action and clinical uses. Ann Review Med. 1997;48(1):129-56.

5. Narvekar N, Critchley HO, Cheng L, Baird DT. Mifepristone induced amenorrhoea is associated with an increase in microvessel density and glucocorticoid receptor and a decrease in stromal vascular endothelial growth factor. Hum Reprod. 2006;21(9): 2312-8.

6. Seth S, Goel N, Singh E, Mathur AS, Gupta G. Effect of mifepristone $(25 \mathrm{mg})$ in treatment of uterine myoma in perimenopausal woman. J Midlife Health. 2013;4(1):22-6.

7. Sinha M, Kyal A, Mukhopadhay P. Effectiveness of Mifepristone in the Treatment of Uterine Leiomyomata. Nepal J Obstet Gynaecol. 2013 ;8(1):22-5.

8. Das SS. Prospective Study on Low-Dose Mifepristone for the Treatment of Leiomyoma: A Hospital Based Study. Int Arch BioMed Clinic Res. 2018 21;4(1):104-6.

9. Eisinger SH, Fiscella J, Bonfiglio T, Meldrum S, Fiscella K. Open-label study of ultra ow-dose mifepristone for the treatment of uterine leiomyomata. European J Obstet Gynecol Reproduct Biol. 2009;146(2):215-8.

10. Arora D, Chawla J, Kochar SP, Sharma JC. A randomized control trial to assess efficacy of Mifepristone in medical management of uterine fibroid. Med J Armed Forces India. 2017;73(3):26773. 
11. Fiscella K, Eisinger SH, Meldrum S, Feng C, Fisher SG, Guzick DS. Effect of mifepristone for symptomatic leiomyomata on quality of life and uterine size: a randomized controlled trial. Obstet Gynecol. 2006;108(6):1381-7.

12. Bagaria M, Suneja A, Vaid NB, Guleria K, Mishra $\mathrm{K}$. Low-dose mifepristone in treatment of uterine leiomyoma: a randomised double-blind placebocontrolled clinical trial. Aust NZJ Obstet Gynaecol. 2009;49(1):77-83.
13. Sudha B, Kumari D. effect of low dose mifepristone in symptomatic uterine leiomyoma. J Evidence Med Healthcare. 2016;3(21):909-13.

Cite this article as: Seher U, Chauhan N, Mangla $M$. Study the effect of mifepristone on clinical symptoms and its side effects in patients with fibroid uterus. Int J Reprod Contracept Obstet Gynecol 2018;7:4853-7. 